\section{Dancing for Parkinson's: A Gateway for Connectedness to Peers and Social Assurance}

\author{
P. Izbicki, t* E. L. Stegemöller, ${ }^{\ddagger}$ J. Compton $\$$, and J. Thompson ${ }^{\pi}$ \\ †John P. Hussman Institute for Human Genomics, University of Miami Miller School of Medicine, \\ Miami, FL 33136; :Department of Kinesiology, " Department of Natural Resource Ecology and \\ Management, and "Office of the Registrar, lowa State University, Ames, IA 50011
}

\begin{abstract}
The first-year student experience in college is a crucial time for personal and professional development, especially for students entering science, technology, education, and mathematics (STEM) disciplines. Unfortunately, it is also the time when students most commonly leave STEM, largely due to disconnection from faculty and peers. The Freshman Research Initiative (FRI) is a program that introduces first-year undergraduates to research in a variety of fields. The program has shown positive outcomes for student success and retention in STEM fields. However, it has not been demonstrated whether this program can increase social connectedness and assurance, potentially contributing to students' longer-term retention in STEM. In this pilot study, we measured social connectedness/assurance among students before and after a 16 -week course in neurophysiology. We found that combined scores of social connectedness and assurance significantly increased by the end of the course. We also found that individual constructs of social connectedness and assurance significantly increased. Furthermore, the majority of students from FRI were retained in STEM fields. We plan future studies to include collection of longitudinal data and measures to identify additional reasons that the FRI increased these positive outcomes among our student participants.
\end{abstract}

\section{INTRODUCTION}

The first-year experience in the university setting is a critically important time for students' personal development as well as for their professional and career development. This is particularly true for students enrolled in majors and considering eventual careers in science, technology, engineering, and mathematics (STEM). Students who leave often indicate that lack of faculty-student interaction, lack of preparation for and poor organization of teaching, and the monotony of typical lecture-based approaches in STEM classrooms are reasons for their departure (Watkins and Mazur, 2013). Furthermore, most students who leave STEM fields do so during their first or second year (Seymour and Hewitt, 1997) and report that bad experiences in their freshman science courses are most influential in their decisions (Manis et al., 1989). On the other hand, previous research suggests that summer bridge sessions, supplemental courses, externally funded undergraduate research programs, and department-wide student mentoring and support systems can actually help retain students in these fields (Turner and Thompson, 2014; Schneider et al., 2015; Bowman and Holmes, 2018; Nerio et al., 2019). Research has also shown that student retention in STEM depends on their formation of strong interpersonal relationships with older, more experienced peers and faculty members (Gregerman et al., 1998; (Watkins and Mazur, 2013). A combination of a formal undergraduate research experience early in college and faculty/peer mentoring would thus be likely to produce more positive results for STEM retention.
Graham Hatfull, Monitoring Editor Submitted May 28, 2020; Revised Feb 22, 2021: Accepted Mar 8, 2021

CBE Life Sci Educ June 1, 2021 20:ar27 DOI:10.1187/cbe.20-05-0101

*Address correspondence to: P. Izbicki (pizbicki@ med.miami.edu).

(c) 2021 P. Izbicki et al. CBE-Life Sciences Education $\odot 2021$ The American Society for Cell Biology. This article is distributed by The American Society for Cell Biology under license from the author(s). It is available to the public under an Attribution-Noncommercial-Share Alike 3.0 Unported Creative Commons License (http://creativecommons.org/licenses/ by-nc-sa/3.0)

"ASCB®" and "The American Society for Cell Biology $\circledR^{\prime \prime}$ are registered trademarks of The American Society for Cell Biology. 
Undergraduate research experiences have been found to be among a set of high-impact, evidence-based practices (Kuh, 2008) that are also beneficial for increasing student interest in STEM (Russell et al., 2007) and retaining students in the STEM disciplines (Nagda et al., 1998; Lopatto, 2007; Nerio et al., 2019). Researchers also report gains in independence, greater intrinsic motivation to learn, and increased participation in classes among students who have been engaged in research activities (Lopatto, 2007; Nerio et al., 2019). Additionally, research experiences within the first 2 years of undergraduate education have been shown to increase STEM retention and graduation rates (Nerio et al., 2019). Thus, undergraduate research experiences early in students' programs are extremely beneficial for both their academic and personal development.

The Freshman Research Initiative (FRI) is a course-based undergraduate research experience that was developed at the University of Texas-Austin (Simmons, 2012). The goal of the program is to increase the persistence of students pursuing STEM programs and careers. There are multiple FRI research areas within STEM, referred to as "research streams" (Beckham et al., 2015). Students are able to choose a stream aligned with their career interests and goals. In each stream, there are between eight and 40 undergraduate students who work on a scientific problem with mentoring from a $\mathrm{PhD}$-level graduate student and a faculty member (often the principal investigator). Although each FRI program and stream is unique, the core elements of the program are to include a research experience that exposes students to core science concepts and research skills in a particular field while making meaningful scientific contributions such as sharing authorship on peer-reviewed publications (Walcott et al., 2018).

At Iowa State University, FRI is implemented as a semester-long course that gives freshman students a research experience in a lab of their choosing. It allows freshman undergraduates (either declared in STEM majors or undeclared) to enroll in research credits that can apply to their degrees in the fields of chemistry, chemical engineering, biology, bioinformatics/computational biology, molecular biology, neurophysiology, genetics, and physics. These streams each contain from 15 to 20 students and allow for a flexible curriculum with respect to content and format. A stream might include extensions of inquiry-based labs, class-wide linked projects, and/or separate classes integrated with specific research in faculty members' laboratories. The core of the FRI is a guided experience through the research process, in which students design their own experiments and produce posters summarizing their projects that are suitable for presentation at a conference and/or university-sponsored research symposium.

Students in FRI also meet with other students interested in research, experience the day-to-day life of a scientist, generate their own data, learn about various fields of research within their majors, and explore opportunities to conduct further research during their undergraduate careers. FRI allows for close collaboration with faculty, graduate students, and peers, as is common in a research lab. This program has been implemented across the United States at other universities and colleges, with positive outcomes reported for student success and retention in STEM (Simmons, 2014; Beckham et al., 2015; Cromley et al., 2016; Mervis, 2016; Rodenbusch et al., 2016; Hernandez et al., 2018). In several streams (including our own), students have the opportunity to apply research in both lab and clinical settings, and thus envision themselves as impactful clinical scientists (Hunter et al., 2007; Carpi et al., 2017; Nerio et al., 2019). Furthermore, FRI experiences have also been shown to generate returns for students in the form of increased future earning potential after graduation (Walcott et al., 2018). However, we are unaware of previous research to determine whether the FRI experience can also enhance social connectedness and assurance among participants.

Belonging is a crucial basic psychological need (Maslow, 1943) and essential human motivator (Covington 2000; Eccles and Wigfield, 2002; Arslan, 2020). Riley and White (2016) define it as feeling accepted, appreciated, and understood in relationships with individuals and groups of people. Belongingness within the context of education is fundamental for success both in and out of the classroom (Covington 2000; Eccles and Wigfield, 2002). This is especially true for academic success during the undergraduate years, which are filled with significant career and social changes (Robbins et al., 2004; Kuh et al., 2008; Asher and Weeks, 2014; Brouwer et al., 2019; Arslan, 2020). Belonging has been related to positive motivational and achievement outcomes in academics (Walton and Cohen, 2007). Additionally, studies have shown that a greater sense of belonging is associated with fewer negative mental health outcomes, including decreased loneliness, depression, and anxiety (Asher and Weeks, 2014). Furthermore, greater belonging has been shown to be a protective factor in psychological health (e.g., depression, anxiety, suicidal ideation; O'Keeffe, 2013; Stebleton et al., 2014). In short, belonging is critical for both psychological health and academic success in college.

Lee and Robbins (1995) describe social connectedness as a phenomenon that "appears to be related to one's opinion of self in relation to other people," while social assurance "appears to be related to one's reliance on other people." Together, these researchers developed a measurement tool, the "Social Connectedness and Social Assurance Scale," to quantify this construct (Lee and Robbins, 1995). Social connectedness and assurance have been shown to play a role in controlling anxiety, depression, and stress, as well as improving self-esteem and social identity in college students (Lee and Robbins, 1998; Lee et al., 2002; Williams and Galliher, 2006). They also have positive relationships with academic performance, well-being, self-efficacy, and retention in undergraduate education (Yeh and Inose, 2003; Pym et al., 2011; Eagan et al., 2013; Wilson et al., 2015; Mahatmya et al., 2018). A sense of belonging has been shown to be important for the retention of women and underrepresented minorities in particular in the STEM fields (Brainard and Carlin, 1998; Cheryan et al., 2009; Good et al., 2012). Thus, social connectedness and assurance may be key for successful development and retention of students in STEM.

At Iowa State University in the Department of Kinesiology, undergraduate students often anecdotally indicate that they feel disconnected from faculty members, graduate students, and their own peers within the department. Previous research indicates that this is occurring not only at Iowa State, but at institutions of higher education all across the United States ((Watkins and Mazur, 2013). This lack of integration and isolation of students within academic institutions has been identified as a crucial factor limiting student retention (Gregerman et al., 1998). 
TABLE 1. Requirements and semester plan for the FRI program Dancing for Parkinson's

\begin{tabular}{ll}
\hline Week & \multicolumn{1}{c}{ Freshman research stream topics } \\
\hline 1 & Ice Breakers, Introduction to Research, Introduction to Mentors, Lab Tour, Social Connectedness Survey (Pre) \\
2 & Considerations for Human Subjects Research \& How to Read Journal Reviews \\
3 & Developing a Research Question and Design \& Journal Reviews \\
4 & What Is Parkinson's Disease Lecture \& Guest with Parkinson's Disease \\
5 & What Is Electroencephalography Lecture with Hands-On Application \\
6 & What Is Electromyography, Kinematics, \& Gait Lecture with Hands-On Application \\
7 & What Is Transcranial Magnetic Stimulation with Hands-On Application \\
8 & Decision on Research Projects \\
9 & Data Collection Prep, Run-Through, and Approval \\
10 & Data Collection \\
11 & Data Collection \\
12 & Preparing a Poster Presentation \& Data Analysis \\
13 & Data Analysis \\
14 & Data Analysis \\
15 & Reflections and Goals for Moving Forward, Social Connectedness Survey (Post) \\
\hline
\end{tabular}

The main purpose of our pilot project was to determine whether the Kinesiology FRI at Iowa State increased students' sense of social connectedness and assurance, and whether it contributed to their retention in STEM fields. We hypothesized that participation in the Kinesiology FRI would enhance students' social connectedness and assurance, leading to other positive outcomes for students, and increase their retention in STEM.

\section{METHODS}

\section{Participants}

Twenty-seven healthy young adults between ages 18 and 25 enrolled in the FRI Dancing for Parkinson's program. Thirty-one healthy young adults age-matched, gender-matched, and major-matched enrolled in the University Honors Program at Iowa State University were used as a comparison group for retention. This was an appropriate comparison group, because Honors Program students were required to be exposed to research experiences during their first year. All procedures performed in studies involving human participants were completed in accordance with the ethical standards of Iowa State University and with the 1964 Helsinki Declaration and its later amendments or comparable ethical standards.

\section{Freshman Research Initiative Program-Dancing for Parkinson's}

The FRI program consisted of 15 weeks of course instruction focused on research methods to examine neural motor control in persons with Parkinson's Disease, and how various treatment strategies (i.e., music therapy, singing, dancing, boxing, yoga) could improve movement. In addition, students learned methods for measuring associated brain activity, as well as quality of life and cognitive measures. Students had hands-on experiences volunteering for at least one outreach group involving singing, movement and music, boxing, or yoga for persons with Parkinson's disease. Students also were required to attend weekly in-class meetings and lab meetings (with all lab staff), led by a PhD-level student and/or the principal investigator of the lab, to gain information on current literature and methodology. For the weekly in-class meetings, the PhD-level student was present at all meetings, while the principal investigator was present weeks 1,8 , and 14 . For the weekly lab meetings, the principal investigator led and was present from week 1 through week 16. Individual meetings with either the principal investigator or graduate student were optional and as needed for the students. Hands-on data collection and analysis experiences also were included to give students an introduction to literature, methods, and analysis in this area of research while they were actively engaging with persons with Parkinson's disease in a clinical and research setting (Table 1).

\section{Data Collection}

Social connectedness and social assurance were assessed using the previously validated Social Connectedness and Social Assurance Scales (Lee and Robbins, 1995). There were seven students out of 27 that chose to not complete the survey. Surveys were administered to 20 students who enrolled in the course, both before and after their experiences in the FRI (Table 1). The instrument consisted of 16 items that students rated on a sixpoint scale ( $1=$ strongly agree to $6=$ strongly disagree). The instrument consisted of two factors: social connectedness (factor 1 ) and social assurance (factor 2). Factor 1 consisted of items from all three aspects of belongingness: connectedness (four items), affiliation (three items), and companionship (one item). Higher scores reflected a greater (self-reported) sense of social connected and belongingness. Factor 2 consisted of companionship (four items) and affiliation items (four items). The items represent a general need for reassurance from one or more persons for a sense of belongingness. Higher scores indicate a greater (self-reported) sense of assurance or confidence in social situations. The first eight items on the questionnaire represent social connectedness, while the second eight items on the questionnaire represent social assurance. The Social Connectedness Scale and the Social Assurance Scale each has a maximum score of 48 points and a minimum score of 16 points (Lee and Robbins, 1995).

We also determined and documented whether or not students stayed in STEM and/or a research lab at Iowa State University after their FRI experiences. FRI retention was compared with an age-matched, gender-matched, and majormatched group from the University Honors Program at Iowa State University. Data on retention of both groups were provided from the Office of the Registrar at Iowa State University. 


\section{Data Analysis}

We calculated total scores for the instrument (i.e., totals for Social Connectedness Scale and Social Assurance Scale) and the two scales combined. Then, the total score was averaged across the 20 participants. We decided to combine the scores from the Social Connectedness Scale and Social Assurance Scale due to moderate correlation between the two constructs (0.34; Lee and Robbins, 1995). Mean scores across participants were also determined for each statement to assess which specific elements changed from pre- to postcourse responses. Percentages of retained students in STEM were calculated in both the FRI and University Honors Program groups.

\section{Statistical Analyses}

Statistical analyses were completed in IBM SPSS Statistics for Windows v. 25.0 (IBM Corporation, Armonk, NY, USA). Normality of data was determined using the Shapiro-Wilk test. Due to the total for Social Connectedness being nonnormal, a Wilcoxon signed-rank test was used to determine whether there were pre- and postparticipation differences. Because the Social Connectedness and Social Assurance combined total and Social Assurance total were normal, paired $t$ tests were completed to determine whether there were pre- and postparticipation differences. Statistical significance for both tests was set at $\alpha=0.05$.

As an exploratory analysis, Wilcoxon signed-rank tests for nonnormal data or paired $t$ tests for normal data were performed for each statement in the instrument to determine whether a particular component was driving our results. Normality of data was determined using the Shapiro-Wilk test. Specifically, paired $t$ tests were conducted on statement 10 and statement 15 in Table 2, while Wilcoxon signed-rank tests were conducted on all the other statements. Statistical significance was set at $\alpha=0.05$. Additionally, Cronbach's alpha was used to assess the internal consistency pre- and postcourse.

We determined the percentage of students who had taken the course who then continued in STEM majors and/or in conducting research. Using the Mann-Whitney $U$-test, we compared the STEM major retention in the FRI group with the STEM major retention in the Honors Program group. Statistical significance was set at $\alpha=0.05$.

\section{RESULTS}

The paired $t$ test showed a significant increase from pre- to postcourse responses for total survey scores; $t(19)=-5.08, p$ $<0.001$ (Figure 1A). The Wilcoxon signed-rank test showed a significant increase from pre- to postcourse response for the Social Connectedness score; $Z=-3.60, p<0.001$ (Figure $1 \mathrm{~B})$. The paired $t$ test showed a significant increase from preto postcourse response for the Social Assurance score; $t(19)$ $=-2.16, p<0.044$ (Figure 1C). For the exploratory analysis of each statement, there was only one significant decrease, for the statement "I join groups more for the friendship than the activity itself"; $t(19)=-2.46, p<0.024$ (Table 2, Statement 15). There were a couple of statements trending toward significance for the statements: "I have no sense of togetherness with my peers," $Z=-1.79, p<0.073$ (Table 2, Statement 4); and "It's hard for me to use my skills and talents without someone beside me," $Z=-1.66, p<0.096$ (Table 2, Statement 13).
Previously, the Social Connectedness Scale generated a high internal consistency of 0.91 (Lee and Robbins, 1995). The Social Assurance Scale generated a lower internal consistency of 0.77 (Lee and Robbins, 1995). In this study, Cronbach's alpha coefficients for Social Connectedness Scale and Social Assurance Scale were calculated as 0.90 and 0.84 , respectively.

For students in the FRI group, 23 of 27 students (85\%) remained in STEM majors. Of the same 27 students, 20 (74\%) were continuing in STEM-related research. For the matched students in the Honors Program group, 27 of 31 students (87\%) remained in STEM majors. The Mann-Whitney $U$-test did not demonstrate significant differences in retention between the FRI group and Honors group $(U=428, p=0.878)$.

\section{DISCUSSION}

The main purpose of this pilot project was to determine whether students' singular FRI experience in the course Dancing for Parkinson's increased their social connectedness and assurance, and whether their enrollment would influence retention in STEM and in STEM undergraduate research. We hypothesized that participation in the FRI would enhance students' social connectedness and assurance and support their retention in STEM undergraduate research. Both of our hypotheses were supported by participants' pre- and postparticipation responses. Total and combined scores for social connectedness and assurance increased following their participation, and retention in STEM was maintained. Of our respondents, $85 \%$ continued on in STEM majors and 74\% continued with STEM-related research. However, there were no differences in retention between the FRI group and the Honors group. Additionally, Cronbach's alpha coefficient generated high internal consistency for both scales among this cohort.

Previous research has indicated that summer bridge sessions, supplemental courses, externally funded undergraduate research programs, and department-wide student mentoring systems can all support students in STEM fields (Turner and Thompson, 2014; Schneider et al., 2015; Bowman and Holmes, 2018; Nerio et al., 2019). Furthermore, research has also shown that retaining students in STEM is dependent on formation of strong interpersonal relationships with more experienced peers (Watkins and Mazur, 2013). Thus, our findings that demonstrate increases in social connectedness and assurance along with retention in STEM are consistent with previous findings and assertions that have been made in the literature. However, inasmuch as we are aware, this is the first study to measure the effectiveness of the FRI model (which is used in a number of institutions in the United States) to provide evidence based on social constructs for that phenomenon. Furthermore, the lack of difference in STEM retention observed between the FRI and Honors group suggests that, in addition to research experiences, there are other factors involved in successfully retaining students in STEM.

Our pilot study reveals that social assurance may be a particularly strong driver for students' retention in STEM. Academic and social integration for college students has been strongly identified as important to academic success (e.g., Tinto, 1987). Specifically, students who attend research-intensive universities report a greater need for social acceptance and assurance (to belong and be valued, as per Baldwin et al., 2017). Previous research has also shown that, when students work together with 
TABLE 2. Respondents' level of agreement with Social Connectedness and Social Assurance statements (from Lee and Robbins, 1995), and means, SDs, and $p$ values for Wilcoxon signed-rank or paired $t$ tests comparing pre- and postparticipation responses

\begin{tabular}{|c|c|c|c|c|}
\hline Measure & Statement & Pre Mean (SD) & Post Mean (SD) & $p$ value \\
\hline & Overall total & $68.3(6.9)$ & $79.9(8.6)$ & $<0.001$ \\
\hline & Social Connectedness total & $37.5(5.1)$ & $45.0(3.9)$ & $<0.001$ \\
\hline & Social Assurance total & $30.8(5.4)$ & $35.0(6.7)$ & 0.044 \\
\hline 1 & I feel disconnected from the world around me. ${ }^{\mathrm{a}}$ & $5.3(0.9)$ & $5.6(0.5)$ & 0.130 \\
\hline 2 & Even around people I know, I don't feel that I really belong. ${ }^{a}$ & $5.2(1.2)$ & $5.4(0.9)$ & 0.495 \\
\hline 3 & I feel so distant from people. ${ }^{a}$ & $5.3(1.0)$ & $5.6(0.6)$ & 0.292 \\
\hline 4 & I have no sense of togetherness with my peers. ${ }^{a}$ & $5.1(0.9)$ & $5.6(0.6)$ & 0.073 \\
\hline 5 & I don't feel related to anyone. ${ }^{\mathrm{a}}$ & $5.7(0.7)$ & $5.6(0.5)$ & 0.739 \\
\hline 6 & I catch myself losing all sense of connectedness with society. ${ }^{\mathrm{a}}$ & $5.6(0.6)$ & $5.7(0.5)$ & 0.564 \\
\hline 7 & Even among my friends, there is no sense of brother/sisterhood. ${ }^{a}$ & $5.5(0.9)$ & $5.8(0.4)$ & 0.107 \\
\hline 8 & I don’t feel that I participate with anyone or any group. ${ }^{\mathrm{a}}$ & $5.7(0.5)$ & $5.8(0.5)$ & 0.480 \\
\hline 9 & I feel more comfortable when someone is constantly with me. ${ }^{b}$ & $4.0(1.3)$ & $4.4(1.0)$ & 0.249 \\
\hline 10 & I'm more at ease doing things together with other people. ${ }^{\mathrm{b}}$ & $2.7(1.0)$ & $3.4(1.3)$ & 0.124 \\
\hline 11 & Working side-by-side with others is more comfortable than working alone. ${ }^{b}$ & $3.2(1.3)$ & $3.5(1.1)$ & 0.436 \\
\hline 12 & My life is incomplete without a buddy beside me. ${ }^{b}$ & $4.4(1.2)$ & $4.9(1.1)$ & 0.210 \\
\hline 13 & It's hard for me to use my skills and talents without someone beside me. ${ }^{b}$ & $5.0(0.8)$ & $5.4(0.7)$ & 0.096 \\
\hline 14 & I stick to my friends like glue. ${ }^{\mathrm{b}}$ & $4.1(1.2)$ & $4.6(1.4)$ & 0.237 \\
\hline 15 & I join groups more for the friendship than the activity itself. ${ }^{b}$ & $3.1(1.0)$ & $4.2(1.5)$ & 0.024 \\
\hline 16 & I wish to find someone who can be with me all the time. ${ }^{\mathrm{b}}$ & $4.5(1.1)$ & $4.8(1.3)$ & 0.552 \\
\hline
\end{tabular}

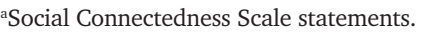

'Social Assurance Scale statements.

peers and faculty mentors in research, they also have more confidence in their academic skills and performance (Levis-Fitzegerald et al., 2005; Hall et al., 2018; Nerio et al., 2019). The Dancing for Parkinson's FRI required that students work in teams to plan, conduct, and present their research projects to one another and an outside audience. Thus, students are collaborating with three to five other peers during the semester. In the outreach program, assisting patients is often done in groups of two volunteers. Furthermore, as the semester continued, students would often interact with one another before and after class. These components may affect the participating students' feelings of social connectedness and assurance. The fact

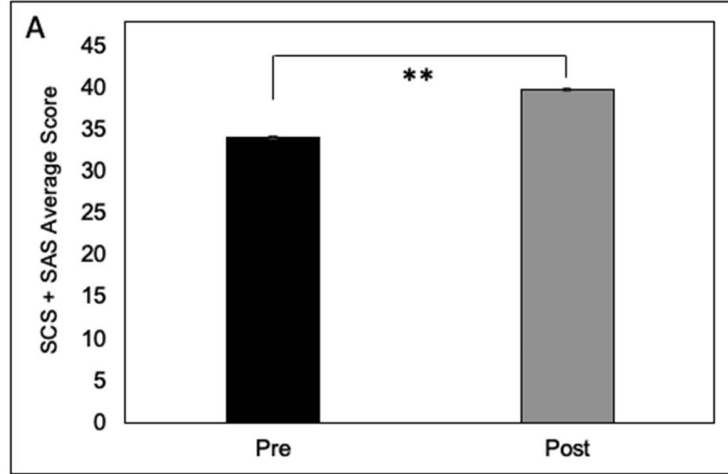

FIGURE 1. (A) Social Connectedness Scale (SCS) and Social Assurance Scale (SAS) score combined $(n=20)$. (B) SCS construct Score ( $n=20)$. (C) SAS construct score $(n=20)$. Error bars reflect standard error. ${ }^{*} p=0.044 ;{ }^{* *} p<0.001$. 
that the students in our course were able to be a part of the translation of the research may also have contributed to their perceived social assurance. In other words, students were able to apply their research questions in both lab and clinical settings and thus envision themselves as clinical scientists (Hunter et al., 2007; Carpi et al., 2017; Nerio et al., 2019).

We are not aware of other programs like this for students so early in their undergraduate careers at Iowa State (or possibly even other institutions). We surmise students felt more valued and connected to their peers through their experiences together with patients with Parkinson's disease as well as senior peers and faculty mentors. Students may have recognized their research and outreach contributions were making a difference, potentially leading to a sense of ownership for their work in both the lab and clinic at a very early stage of their academic programs. Others have suggested that a sense of ownership of research (e.g., discovery, iteration, and collaboration) can have significant positive outcomes for FRI students (i.e., Corwin et al., 2018). Furthermore, we speculate that this may also contribute to both the high STEM major and STEM-related research retention rates. This phenomenon has been reported from other institutions employing FRI as well (Cahalan, 2011; Peterson, 2012; Simmons, 2012).

We acknowledge several limitations to this study. First, we do not have longitudinal data that extend postgraduation to show whether students stay in STEM-related fields or go on to professional/graduate schools. Thus, this study serves only as a pilot and warrants further investigation with a larger sample size. Second, we do not understand from this study exactly why it is that social connectedness and assurance increased (e.g., from the students' perspectives). Was it due to greater contact with faculty and peers, or was it due to other components of the course? Was it due to other experiences during freshman year not necessarily related to the course? Planned follow-up studies using both quantitative and qualitative (e.g., focus groups and pre/post interviews) analyses will allow us to address these issues using longitudinal data from collection of postgraduation information and additional surveys and/or interviews. Third, we do not have comparison data from other FRI courses across the United States. It would be imperative to establish collaborations with institutions across the country to provide a consistent framework for creating a FRI to increase transferability and replicability across sites.

In summary, our data indicate that, after their experience with our FRI program, students' responses indicated an increase in social connectedness and assurance and strong retention in STEM and STEM research. This supports previous research showing that this and similar programs have potential to support first-year college students and introduce them to the joys, challenges, and relevance of STEM and STEM research in a supportive, encouraging, and engaging environment.

\section{ACKNOWLEDGMENTS}

Thank you to all the undergraduates who participated in the course and continued to be an inspiration for us to keep FRI alive at our institution. FRI was funded by the Howard Hughes Medical Institute Engage to Excel grant, Iowa State University College of Liberal Arts and Sciences, and Iowa State University Office of the Provost.

\section{REFERENCES}

Arslan, G. (2020). Loneliness, college belongingness, subjective vitality, and psychological adjustment during coronavirus pandemic: Development of the College Belongingness Questionnaire. Journal of Positive School Psychology, 5(1), 17-31.

Asher, S. R., \& Weeks, M. S. (2014). Loneliness and belongingness in the college years. In Coplan, R. J., Bowker, J. C., \& Nelson, L. J. (Eds.), The Handbook of Solitude: Psychological Perspectives on Social Isolation, Social Withdrawal, and Being Alone (pp. 283-301). Malden, MA: John Wiley \& Sons, Ltd.

Baldwin, D. R., Towler, K., Oliver, M. D., \& Datta, S. (2017). An examination of college student wellness: A research and liberal arts perspective. Health Psychology Open, 4(2), 2055102917719563.

Beckham, J. T., Simmons, S., Stovall, G. M., \& Farre, J. (2015). The Freshman Research Initiative as a model for addressing shortages and disparities in STEM engagement. In Rubinstein, Y. A., \& Peterson, M. A. (Eds.), Directions for Mathematics Research Experience for Undergraduates (pp. 181-212). Hackensack, NJ: World Scientific.

Bowman, N. A., \& Holmes, J. M. (2018). Getting off to a good start? First-year undergraduate research experiences and student outcomes. Higher Education, 76(1), 17-33.

Brainard, S. G., \& Carlin, L. (1998). A six-year longitudinal study of undergraduate women in engineering and science. Journal of Engineering Education, 87(4), 369-375.

Brouwer, J., Jansen, E., Severiens, S., \& Meeuwisse, M. (2019). Interaction and belongingness in two student-centered learning environments. International Journal of Educational Research, 97, 119-130.

Cahalan, R. (2011, September 20). Research program boosts student retention dramatically. Alcalde. https://alcalde.texasexes.org/2011/09/ research-program-boosts-student-retention-dramatically

Carpi, A., Ronan, D. M., Falconer, H. M., \& Lents, N. H. (2017). Cultivating minority scientists: Undergraduate research increases self-efficacy and career ambitions for underrepresented students in STEM. Journal of Research in Science Teaching, 54(2), 169-194.

Cheryan, S., Plaut, V. C., Davies, P. G., \& Steele, C. M. (2009). Ambient belonging: How stereotypical cues impact gender participation in computer science. Journal of Personality and Social Psychology, 97(6), 1045.

Covington, M. V. (2000). Goal theory, motivation, and school achievement: An integrative review. Annual Review of Psychology, 51(1), 171-200.

Cromley, J. G., Perez, T., \& Kaplan, A. (2016). Undergraduate STEM achievement and retention: Cognitive, motivational, and institutional factors and solutions. Policy Insights from the Behavioral and Brain Sciences, 3(1), 4-11.

Corwin, L. A., Runyon, C. R., Ghanem, E., Sandy, M., Clark, G., Palmer, G. C., .. \& Dolan, E. L. (2018). Effects of discovery, iteration, and collaboration in laboratory courses on undergraduates' research career intentions fully mediated by student ownership. CBE-Life Sciences Education, 17(2), ar20.

Eagan, M. K. Jr., Hurtado, S., Chang, M. J., Garcia, G. A., Herrera, F. A., \& Garibay, J. C. (2013). Making a difference in science education: the impact of undergraduate research programs. American Educational Research Journal, 50(4), 683-713.

Eccles, J. S., \& Wigfield, A. (2002). Motivational beliefs, values, and goals. Annual Review of Psychology, 53(1), 109-132.

Good, C., Rattan, A., \& Dweck, C. S. (2012). Why do women opt out? Sense of belonging and women's representation in mathematics. Journal of Personality and Social Psychology, 102(4), 700.

Gregerman, S. R., Lerner, J. S., Von Hippel, W., Jonides, J., \& Nagda, B. A (1998). Undergraduate student-faculty research partnerships affect student retention. Review of Higher Education, 22(1), 55-72.

Hall, E. E., Walkington, H., Shanahan, J. O., Ackley, E., \& Stewart, K. A. (2018) Mentor perspectives on the place of undergraduate research mentoring in academic identity and career development: An analysis of award winning mentors. International Journal for Academic Development, 23(1), $15-27$.

Hernandez, P. R., Woodcock, A., Estrada, M., \& Schultz, P. W. (2018). Undergraduate research experiences broaden diversity in the scientific workforce. BioScience, 68(3), 204-211.

Hunter, A. B., Laursen, S. L., \& Seymour, E. (2007). Becoming a scientist: The role of undergraduate research in students' cognitive, personal, and professional development. Science Education, 91(1), 36-74. 
Kuh, G. D. (2008). Excerpt from high-impact educational practices: What they are, who has access to them, and why they matter. Association of American Colleges and Universities, 14(3), 28-29.

Kuh, G. D., Cruce, T. M., Shoup, R., Kinzie, J., \& Gonyea, R. M. (2008). Unmasking the effects of student engagement on first-year college grades and persistence. The Journal of Higher Education, 79(5), 540-563.

Lee, R. M., Keough, K. A., \& Sexton, J. D. (2002). Social connectedness, social appraisal, and perceived stress in college women and men. Journal of Counseling \& Development, 80(3), 355-361.

Lee, R. M., \& Robbins, S. B. (1995). Measuring belongingness: The social connectedness and the social assurance scales. Journal of Counseling Psychology, 45(3), 338-345.

Lee, R. M., \& Robbins, S. B. (1998). The relationship between social connectedness and anxiety, self-esteem, and social identity. Journal of Counseling Psychology, 42(2), 232.

Levis-Fitzegerald, M., Denson, N., \& Kerfeld, C. A. (2005). Undergraduate students conducting research in the life sciences: Opportunities for connected learning. Proceedings of the Annual Meeting of the Association for the Study of Higher Education Online Submission, 1-36. https://eric .ed.gov/?id=ED491735

Lopatto, D. (2007). Undergraduate research experiences support science career decisions and active learning. CBE-Life Sciences Education, 6(4) 297-306.

Mahatmya, D., Thurston, M., \& Lynch, M. E. (2018). Developing students well-being through integrative, experiential learning courses. Journal of Student Affairs Research and Practice, 55(3), 295-307.

Manis, J. D., Sloat, B. F., Thomas, N. G., \& Davis, C. S. (1989). An analysis of factors affecting choices of majors in science, mathematics and engineering at the University of Michigan. Research Report from Ann Arbor Michigan: Center for the Education of Women, University of Michigan Online Submission, 1-61. https://eric.ed.gov/?id=ED356954

Maslow, A. H. (1943). A theory of human motivation. Psychological Review, 50(4), 370-396

Mervis, J. (2016). Genuine research keeps students in science. Science, 352(6291), 1266

Nagda, B. A., Gregerman, S. R., Jonides, J., Von Hippel, W., \& Lerner, J. S. (1998). Undergraduate student-faculty research partnerships affect studen retention. The Review of Higher Education, 22(1), 55-72.

Nerio, R., Webber, A., MacLachlan, E., Lopatto, D., \& Caplan, A. J. (2019) One-year research experience for associate's degree students impacts graduation, STEM retention, and transfer patterns. CBE-Life Sciences Education, 18(2), ar25

O'Keeffe, P. (2013). A sense of belonging: Improving student retention. College Student Journal, 47(4), 605-613.

Peterson, E. (2012). Making bigger better. HHMI Bulletin, 25(2)

Pym, J., Goodman, S., \& Patsika, N. (2011). Does belonging matter? Exploring the role of social connectedness as a critical factor in students' transition to higher education. Psychology in Society, no. 42, 35-50.
Riley, T., \& White, V. (2016). Developing a sense of belonging through engagement with like-minded peers: A matter of equity. New Zealand Journal of Educational Studies, 51(2), 211-225.

Robbins, S. B., Lauver, K., Le, H., Davis, D., Langley, R., \& Carlstrom, A. (2004) Do psychosocial and study skill factors predict college outcomes? A meta-analysis. Psychological Bulletin, 130(2), 261.

Rodenbusch, S. E., Hernandez, P. R., Simmons, S. L., \& Dolan, E. L. (2016) Early engagement in course-based research increases graduation rates and completion of science, engineering, and mathematics degrees. CBE-Life Sciences Education, 15(2), ar20

Russell, S. H., Hancock, M. P., \& McCullough, J. (2007). Benefits of undergraduate research experiences. Science, 316(5824), 548-549.

Schneider, K. R., Bickel, A., \& Morrison-Shetlar, A. (2015). Planning and implementing a comprehensive student-centered research program for first-year STEM undergraduates. Journal of College Science Teaching, 44(3), 37-43.

Seymour, E., \& Hewitt, N. M. (1997). Talking about leaving. Boulder, CO Westview Press.

Simmons, S. (2014). One institution's approach: How the University of Texas at Austin merges research and teaching through the Freshman Research Initiative (93.1). FASEB Journal, 28(S1), 93-91.

Simmons, S. L. (2012). Critic at large-Learning by doing. Scientist, 26(2), 30.

Stebleton, M. J., Soria, K. M., \& Huesman, R. L. Jr. (2014). First-generation students' sense of belonging, mental health, and use of counseling services at public research universities. Journal of College Counseling, 17(1) $6-20$.

Tinto, V. (1987). Leaving college: Rethinking the causes and cures of student attrition. Chicago, IL: University of Chicago Press

Turner, P., \& Thompson, E. (2014). College retention initiatives meeting the needs of millennial freshman students. College Student Journal, 48(1) 94-104.

Walcott, R. L., Corso, P. S., Rodenbusch, S. E., \& Dolan, E. L. (2018). Benefit-cost analysis of undergraduate education programs: An example analysis of the Freshman Research Initiative. CBE-Life Sciences Education, 17(1), rm1.

Walton, G. M., \& Cohen, G. L. (2007). A question of belonging: Race, social fit and achievement. Journal of Personality and Social Psychology, 92(1), 82.

Watkins, J., \& Mazur, E. (2013). Retaining students in science, technology engineering, and mathematics (STEM) majors. Journal of College Science Teaching, 42(5), 36-41.

Williams, K. L., \& Galliher, R. V. (2006). Predicting depression and self-esteem from social connectedness, support, and competence. Journal of Social and Clinical Psychology, 25(8), 855-874.

Wilson, D., Jones, D., Bocell, F., Crawford, J., Kim, M. J., Veilleux, N., ... \& Plett, M. (2015). Belonging and academic engagement among undergraduate STEM students: A multi-institutional study. Research in Higher Education, 56(7), 750-776.

Yeh, C. J., \& Inose, M. (2003). International students' reported English fluency, social support satisfaction, and social connectedness as predictors of acculturative stress. Counselling Psychology Quarterly, 16(1), 15-28. 